\title{
Topographical distribution of blubber in finless porpoises (Neophocaena asiaeorientalis sunameri): a result from adapting to living in coastal waters
}

\author{
Xianyuan Zeng ${ }^{1,2}$, Junhua $\mathrm{Ji}^{1,2}$, Yujiang Hao ${ }^{1 *}$ and Ding Wang ${ }^{1 *}$
}

\begin{abstract}
Background: Blubber has many functions, among which energy storage, thermoregulation, buoyancy, and hydrodynamic streamlining are the most frequently cited. Within and between taxa, variations in its structure and distribution likely reflect different adaptations of a species to its life history requirements, environment, health, and function. Here, we use ultrasound to describe the distribution of blubber in the finless porpoise (Neophocaena asiaeorientalis sunameri) based on examinations of 34 fresh cadavers recovered as accidental fisheries bycatch.

Results: Measurements of blubber depth determined by ultrasound positively correlated with conventional measurements using a scalpel and calipers. Whereas conventional surgical incision and visual examination revealed two layers of blubber, ultrasound revealed up to three layers; thus, ultrasound reveals additional structural detail in blubber while crude necropsy techniques do not. Across life history categories, ultrasound revealed the distribution of inner blubber to be topographically consistent with that of full-depth blubber. Blubber in the dorsal region was stratified into three layers and was significantly thicker than that in the lateral and ventral regions, in which a middle layer was normally absent.
\end{abstract}

Conclusions: Ultrasound provides a fast, effective, and accurate means to determine blubber thickness and structure, and thus, assessment of the health of fresh finless porpoise carcasses. Blubber depth is determined largely by the thickness of the inner and middle layers, wherein lipids are concentrated. The thickening of blubber in the dorsal thoracic-abdominal region suggests multiple roles of thermal insulation, lipid storage, and, we speculate, to facilitate vertical stability in the complex shallow and estuarine waters in which this animal absent of a dorsal fin occurs.

Keywords: Blubber distribution; Finless porpoise; Cetacean; Postmortem; Ultrasound imaging

\section{Background}

Blubber performs a variety of functions in aquatic mammals, such as acting as an energy reserve, for thermal insulation, providing buoyancy, and streamlining the body (Ryg et al. 1988). Lipids are almost entirely accumulated within this tissue, which can constitute a large proportion of an animal's gross mass (Read 1990). It has become common to assess the condition of marine mammals on the basis of blubber measurements, sometimes in conjunction with other morphological parameters (Gomez-Campos et al. 2011; Miller et al. 2011).

\footnotetext{
* Correspondence: hao.yj@ihb.ac.cn; wangd@ihb.ac.cn

${ }^{1}$ Institute of Hydrobiology, Chinese Academy of Sciences, 7 South Donghu Road, Wuchang District, Wuhan 430072, China

Full list of author information is available at the end of the article
}

Blubber not only performs multiple functions, but these functions may also vary in different regions of an animal. For instance, in ringed seals (Pusa hispida), blubber from the posterior region has been deemed over-insulated and to function primarily as a fat reserve; accordingly, it is from this region that blubber depth should, preferably, be measured to assess body condition (Ryg et al. 1988). Koopman (1998) determined sites of energy storage in harbor porpoises (Phocoena phocoena) to occur predominately in the thoracicabdominal region, whereas that blubber in the tailstock region performed a hydrodynamic role, streamlining the peduncle. Biochemical and histological findings in harbor porpoises and bottlenose dolphins (Tursiops truncatus) have further demonstrated fat deposition and mobilization to 
occur primarily within the inner and middle layers of blubber in the thoracic-abdominal region, whereas the outer comparably metabolically inert layer functions primarily in thermal insulation (Koopman et al. 2002; Samuel and Worthy 2004; Struntz et al. 2004). Given this recognized variation in the roles of blubber within different layers or from different regions of a body in different species, we deem it necessary to have a basic appreciation of the normal topographical distribution of blubber in a given species before otherwise sampling from it - a practice that might lead to obtaining erroneous measures or metrics of body condition.

East Asian finless porpoises (Neophocaena asiaeorientalis sunameri) are one of the smallest odontocetes to occur in coastal waters from the Taiwan Strait north to the Bohai/ Yellow Sea in China, and the waters of Korea and Japan (Jefferson and Wang 2011). Investigations on blubber distribution in this porpoise are required to lay the groundwork for body condition assessment based on metrics of blubber thickness. To obtain baseline data of this nature, two techniques have been commonly used: ultrasound imaging on live animals and necropsy of carcasses (Beck and Smith 1995; Mellish et al. 2007; Montie et al. 2008). However, the number of live finless porpoises available for ultrasound imaging is limited, since captive animals in commercial aquaria are scattered and behavioral training must be undertaken before ultrasound examinations can be performed (Brook 2001). The alternative and more traditional, often unpleasant, and laborious method involves necropsy of carcasses (that are prone to rapid decomposition, especially when laboratories are far away from the field) (Ryg et al. 1990; Heng et al. 2009). Postmortem abdominal ultrasonography is generally considered to be of limited or no value, particularly for highly decomposed cadavers because gas rapidly accumulates in the gastrointestinal tract and blood vessels (Charlier et al. 2013; Heng et al. 2009). Nevertheless, we explore the possibility that ultrasound images of blubber might provide meaningful data, given that abdominal gases might not have the same effect on these tissues in fresh carcasses.

In this present study, we perform ultrasound imaging on 34 finless porpoise carcasses to: 1) validate postmortem ultrasound virtopsy on the blubber layer, 2) describe the distribution of blubber unique to this subspecies, and 3) speculate on the possible adaptive significance of blubber distribution in finless porpoises.

\section{Methods}

\section{Animals}

Finless porpoises are routinely, accidentally caught in gill nets in the Bohai/Yellow Sea. They are usually discovered within a few hours of death. During May of 2014, 34 such animals were recovered from fishing operations in Penglai, Shangdong. All cadavers exhibited no or little scavenger damage and had died within $12 \mathrm{~h}$ of reception; all also appeared to be in good condition, with the exception of neonates, which, according to their external appearance, were very thin. Upon receipt of individuals, ultrasound and physical examinations were performed immediately at a nearby fishing port; animals were weighed and their standard body and girth lengths were measured (American Society of Mammalogists 1961).

Animals were categorized into one of the following life history groups: 1) neonates retaining rostral hairs, unhealed umbilicus, and fetal folds (Dearolf et al. 2000); 2)

Table 1 Individual information of postmortem finless porpoises used in the present study

\begin{tabular}{|c|c|c|c|}
\hline Animal & Total body length $(\mathrm{cm})$ & Life history category & Sex \\
\hline PL51221 & 77.2 & Neonate & $\mathrm{F}$ \\
\hline PL51622 & 77.2 & Neonate & $\mathrm{F}$ \\
\hline PL51925 & 79.8 & Neonate & $\mathrm{F}$ \\
\hline PL51722 & 85.4 & Neonate & $\mathrm{F}$ \\
\hline PL50811 & 72.2 & Neonate & M \\
\hline PL51913 & 82.1 & Neonate & M \\
\hline PL51911 & 82.3 & Neonate & M \\
\hline PL51211 & 83.8 & Neonate & M \\
\hline PL51621 & 107.6 & Juvenile & $\mathrm{F}$ \\
\hline PL51724 & 111.6 & Juvenile & $\mathrm{F}$ \\
\hline PL50821 & 114.1 & Juvenile & $\mathrm{F}$ \\
\hline PL50621 & 114.5 & Juvenile & $\mathrm{F}$ \\
\hline PL51721 & 116.1 & Juvenile & $\mathrm{F}$ \\
\hline PL51522 & 117.5 & Juvenile & $\mathrm{F}$ \\
\hline PL51021 & 119.5 & Juvenile & $\mathrm{F}$ \\
\hline PL51923 & 120.1 & Juvenile & $\mathrm{F}$ \\
\hline PL51723 & 122.6 & Juvenile & $\mathrm{F}$ \\
\hline PL51521 & 123.8 & Juvenile & $\mathrm{F}$ \\
\hline PL52212 & 104.4 & Juvenile & M \\
\hline PL51011 & 111.2 & Juvenile & M \\
\hline PL51711 & 112.9 & Juvenile & M \\
\hline PL52211 & 119.8 & Juvenile & M \\
\hline PL52011 & 120.2 & Juvenile & M \\
\hline PL50812 & 126.8 & Juvenile & M \\
\hline PL50911 & 128.2 & Juvenile & M \\
\hline PL51511 & 140.3 & Adult & M \\
\hline PL51311 & 140.4 & Adult & M \\
\hline PL50711 & 183.2 & Adult & M \\
\hline PL51922 & 140.4 & Adult & $F$ \\
\hline PL51421 & 147.3 & Adult & $\mathrm{F}$ \\
\hline PL51321 & 160.9 & Lactating & $\mathrm{F}$ \\
\hline PL51921 & 172.7 & Lactating & $\mathrm{F}$ \\
\hline PL52021 & 175.1 & Lactating & $\mathrm{F}$ \\
\hline PL51924 & 186.7 & Lactating & $\mathrm{F}$ \\
\hline
\end{tabular}




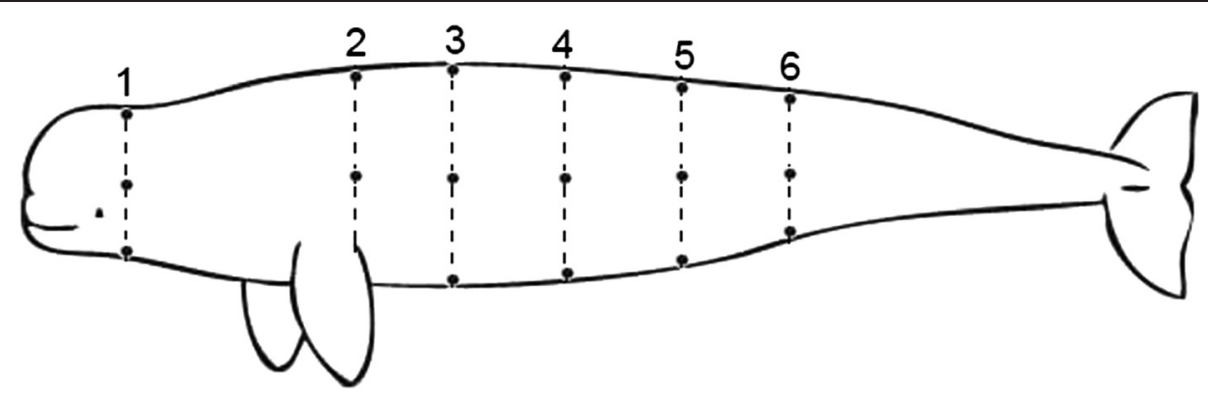

Figure 1 Sites of ultrasound imaging on finless porpoises. Numbers represent girths of the body: (1) head, (2) axillary, (3) mid-thorax, (4) umbilicus, (5) genital slit, and (6) anus. Black spots indicate imaging sites.

juveniles, including both females and males, of body length $<136.7 \mathrm{~cm}$ (calculated on basis of sexual maturation at 5 years of age and the age-length curve established for this population [Gao and Zhou 1993]); 3) adult males of body length $\geq 136.7 \mathrm{~cm}$; 4) lactating females with milk in mammary glands; and 5) other females (neither pregnant nor lactating). Detailed information for these animals is provided in Table 1.

\section{Ultrasound equipment}

A LOGIQ Book XP ultrasound unit (General Electric Co., Schenectady, NY, USA), in combination with a broadband
( 3 to $5 \mathrm{MHz}$ ) curvilinear array transducer, was used to conduct blubber imaging and measurements. All images were stored in a flash disk. Acoustic gel was not required as there is no air layer on the surface of the skin (Brook 2001).

\section{Protocol of ultrasound imaging and validation of blubber imaging}

To determine the distribution of blubber, the body wall (including skin) was imaged at 18 sites (Figure 1). The body was geographically divided into six regions: head (just behind the blowhole), axillary (just caudal insertion of the flipper), mid-thorax (midway between the axillary
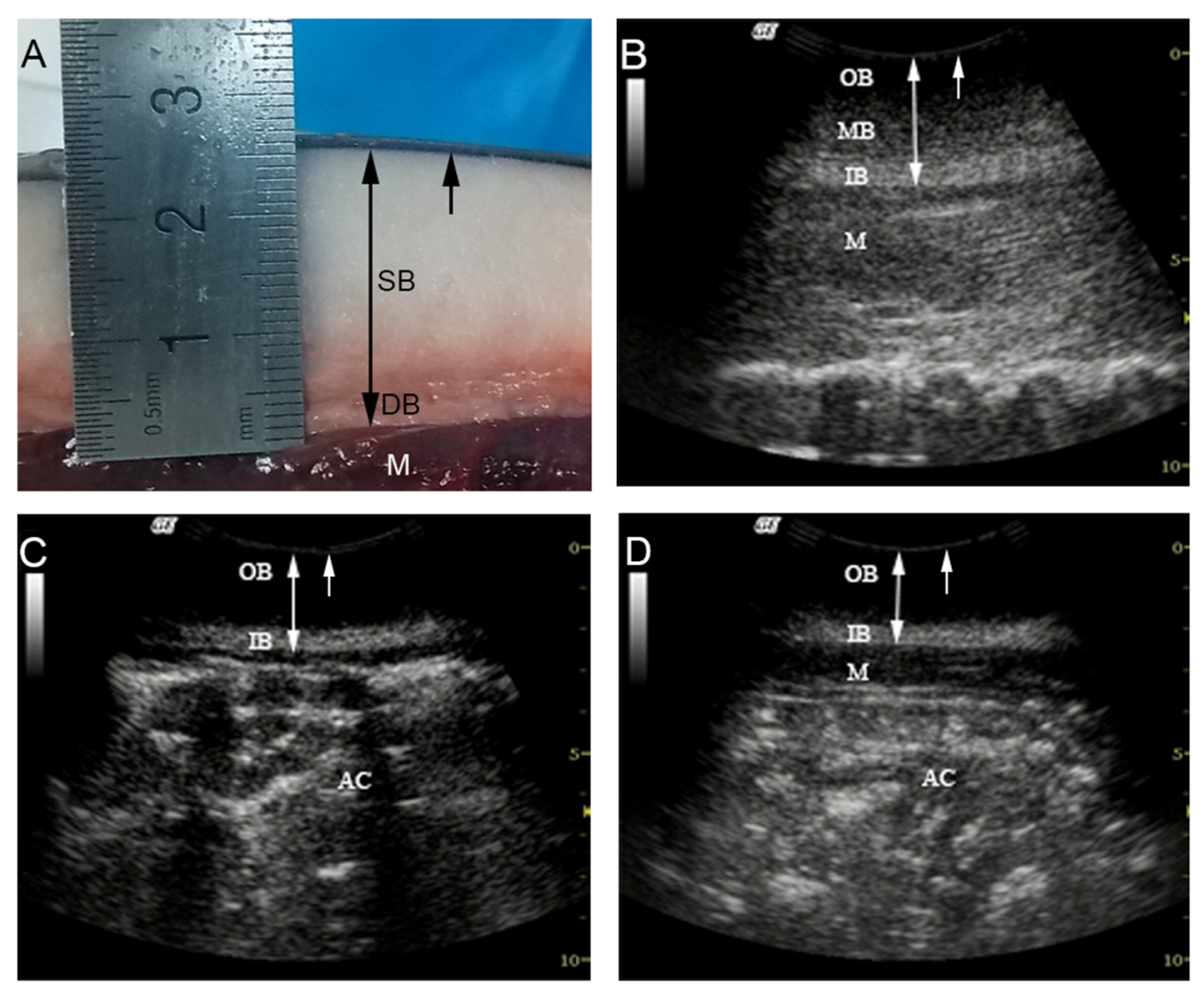

Figure 2 Blubber structure of finless porpoises. (A) A longitudinal section through the blubber layer at the ventral aspect of the umbilicus region. Longitudinal blubber images at the (B) dorsal, (C) lateral, and (D) ventral aspects of the umbilicus region, respectively. Lines with double-headed arrows indicate blubber depth; the arrows indicate the skin layer. AC, abdominal cavity; DB, deep blubber layer; IB, inner blubber layer; M, muscle layer; MB, middle blubber layer; OB, outer blubber layer; SB, superficial blubber layer. Scale marks are in centimeters. 
and umbilicus), umbilicus, genital slit (midway between the umbilicus and anus), and anus regions. Given their bilateral symmetry, imaging was only performed on the left side; carcasses lay laterally, with the transducer perpendicular to the body surface during examination. Blubber was scanned at dorsal, lateral, and ventral aspects of each region. Because of the dorsal midline groove and ridge in these animals, dorsal sites were sampled immediately below the dorsal midline, whereas others were in the lateral and ventral midline of the body (Jefferson and Wang 2011). Blubber measurements were taken from longitudinal images with an ultrasound inbuilt electronic caliper.

To validate blubber measurements of postmortem ultrasound images, a necropsy was carried out following imaging on one randomly selected carcass, on which blubber depth measured by ultrasound was compared with that determined by a steel caliper at 18 sites (Figure 1). This research was licensed by the Ministry of Science and Technology of the People's Republic of China, with all animals procured and examination procedures strictly adhering to Chinese ethical guidelines and legal requirements.

\section{Statistical analysis}

All data analyses were performed with software SPSS 19.0 for Windows (SPSS Inc., Armonk, NY, USA). Normality of data was verified by Shapiro-Wilk test. Kendall's tau-b test was used to compare blubber depth measured by ultrasound unit with that determined by caliper. Intra- or interlife history groups were compared by one-way ANOVA with Student-Newman-Keuls test for post hoc multiple comparisons. The other females (life history category 5) consisted of two individuals only and were excluded from analysis, and the adult males (life history category 3 ) were excluded from comparison among life history groups because this group comprised three individuals only, for which the body length of two was also close to the critical value.

\section{Results}

\section{Blubber structure and measurements in actual and} ultrasound images

Dissection revealed two discrete layers of blubber throughout the entire body, with distinct boundaries between the muscle, the deep and superficial blubber layers, and the skin (Figure 2A); the deep blubber layer close to muscle was structurally heterogeneous and pink colored, whereas that of the superficial blubber was more homogeneous in texture and much lighter in color. Ultrasound similarly revealed multilayered blubber. Blubber in the dorsal region posterior to the head was stratified into three layers (inner, middle, and outer layers) (Figure 2B), in contrast to that blubber in lateral and ventral regions, which was normally absent of the middle layer and consisted of two layers only (Figure 2C,D). The inner layer was significantly hyper-echoic and consistently fascicular, with the boundaries between it and the middle blubber and muscle layers being very clearly defined; the middle layer was relatively hypo-echoic and apparently punctiform, with its echo intensity gradually decreasing towards the outer layer; and the outer layer was anechoic, with its border far from clear from the middle layer. In the head region, only two layers of blubber were apparent, with the inner layer being significantly more hypo-echoic than that of the other regions. Blubber depth determined by ultrasound significantly correlated with actual caliper measurements (Kendall's tau-b test: $\tau=0.634, N=18, P<0.01$ ) (Table 2).

\section{Full-depth blubber}

The distribution of full-depth blubber (combined inner, middle, and out layers) was similar across life history

Table 2 Blubber depths and corresponding ranks through entire body of actual and ultrasound measurements, respectively

\begin{tabular}{|c|c|c|c|c|}
\hline \multirow{2}{*}{$\begin{array}{l}\text { Body region } \\
\text { and aspect }\end{array}$} & \multicolumn{2}{|c|}{ Actual measurements } & \multicolumn{2}{|c|}{ Ultrasound measurements } \\
\hline & $\begin{array}{l}\text { Blubber } \\
\text { depth }(\mathrm{cm})\end{array}$ & Rank & $\begin{array}{l}\text { Blubber } \\
\text { depth }(\mathrm{cm})\end{array}$ & Rank \\
\hline \multicolumn{5}{|l|}{ Head } \\
\hline Dorsal & 1.17 & 1 & 1.23 & 3 \\
\hline Lateral & 1.20 & 2 & 1.16 & 1 \\
\hline Ventral & 1.35 & 3 & 1.20 & 2 \\
\hline \multicolumn{5}{|l|}{ Axillary } \\
\hline Dorsal & 1.85 & 12 & 1.69 & 10 \\
\hline Lateral & 1.79 & 10 & 1.53 & 5 \\
\hline Ventral & 1.68 & 5 & 1.71 & 11.5 \\
\hline \multicolumn{5}{|l|}{ Mid-thorax } \\
\hline Dorsal & 2.38 & 17 & 1.87 & 15 \\
\hline Lateral & 1.80 & 11 & 1.73 & 13 \\
\hline Ventral & 1.78 & 9 & 1.82 & 14 \\
\hline \multicolumn{5}{|l|}{ Umbilicus } \\
\hline Dorsal & 2.49 & 18 & 2.17 & 17 \\
\hline Lateral & 1.75 & 7.5 & 1.67 & 9 \\
\hline Ventral & 1.43 & 4 & 1.59 & 7 \\
\hline \multicolumn{5}{|l|}{ Genital slit } \\
\hline Dorsal & 2.12 & 16 & 2.18 & 18 \\
\hline Lateral & 1.95 & 13.5 & 1.58 & 6 \\
\hline Ventral & 2.05 & 15 & 1.90 & 16 \\
\hline \multicolumn{5}{|l|}{ Anus } \\
\hline Dorsal & 1.95 & 13.5 & 1.71 & 11.5 \\
\hline Lateral & 1.70 & 6 & 1.48 & 4 \\
\hline Ventral & 1.75 & 7.5 & 1.61 & 8 \\
\hline
\end{tabular}




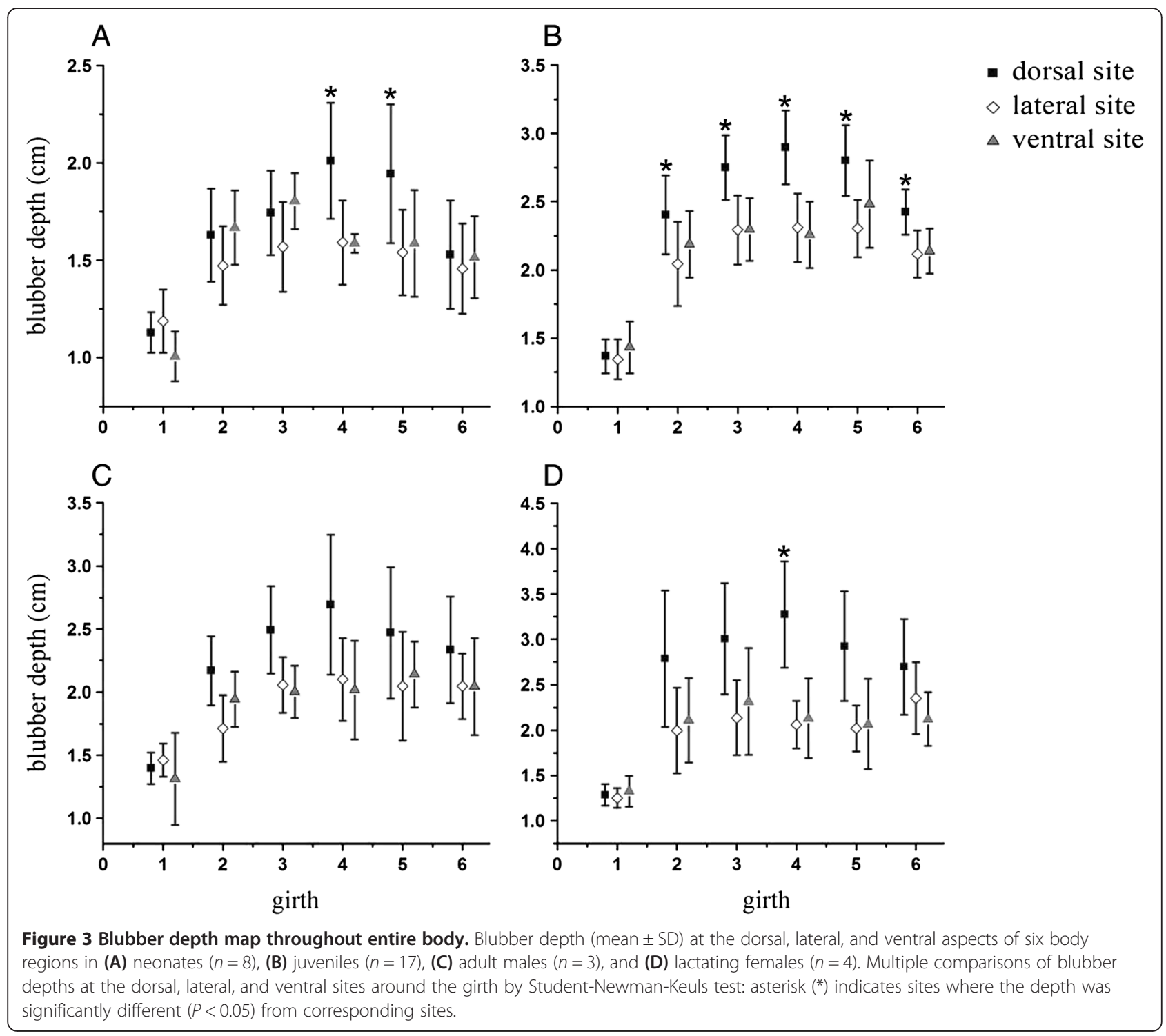

categories (Figure 3). Blubber depth in the head region was consistent and significantly thinner than it was in the posterior regions at corresponding sites (Figure 4). Dorsally, blubber thickness increased gradually from the head, peaked around the umbilical region, and decreased towards the anal area, whereas it was relatively uniform in thickness in both the lateral and ventral regions of the thorax and abdomen. Analysis of variance for a randomized block design revealed that posterior to the head, mean blubber depths of dorsal, lateral, and ventral regions differed significantly across life history groups (neonates: $\quad F_{2,134}=8.639, \quad P<0.01 ;$ juvenile: $F_{2,289}=$ 66.165, $P<0.01$; adult males: $F_{2,46}=7.360, P<0.05$; lactating females: $\left.F_{2,64}=17.093, P<0.01\right)$. Furthermore, mean blubber depth was significantly thicker from the dorsal region (neonates: $1.66 \mathrm{~cm}$, juveniles: $2.46 \mathrm{~cm}$, adult males: $2.26 \mathrm{~cm}$, and lactating females: $2.66 \mathrm{~cm}$ ) than that from both lateral (neonates: $1.47 \mathrm{~cm}$, juveniles: $2.11 \mathrm{~cm}$, adult males: $1.90 \mathrm{~cm}$ and lactating females: $1.97 \mathrm{~cm}$ ) and ventral regions (neonates: $1.53 \mathrm{~cm}$, juveniles: $2.14 \mathrm{~cm}$, adult males: $1.91 \mathrm{~cm}$ and lactating females: $2.01 \mathrm{~cm}$ ) (Student-Newman-Keuls test, $P<0.05$ ); no significant difference was found between the lateral and ventral regions. Dorsal blubber was thicker around the girth than at the corresponding lateral and ventral sites, but the significance in differences of thickness varied throughout the thoracic-abdominal region, and no difference was found between the lateral and ventral sites (Figure 3). Among life history categories, blubber depth of neonates was the thinnest at almost all sites (Table 3). Blubber of lactating females was thicker at the dorsal thoracic and abdominal sites than that of the juveniles, although a 


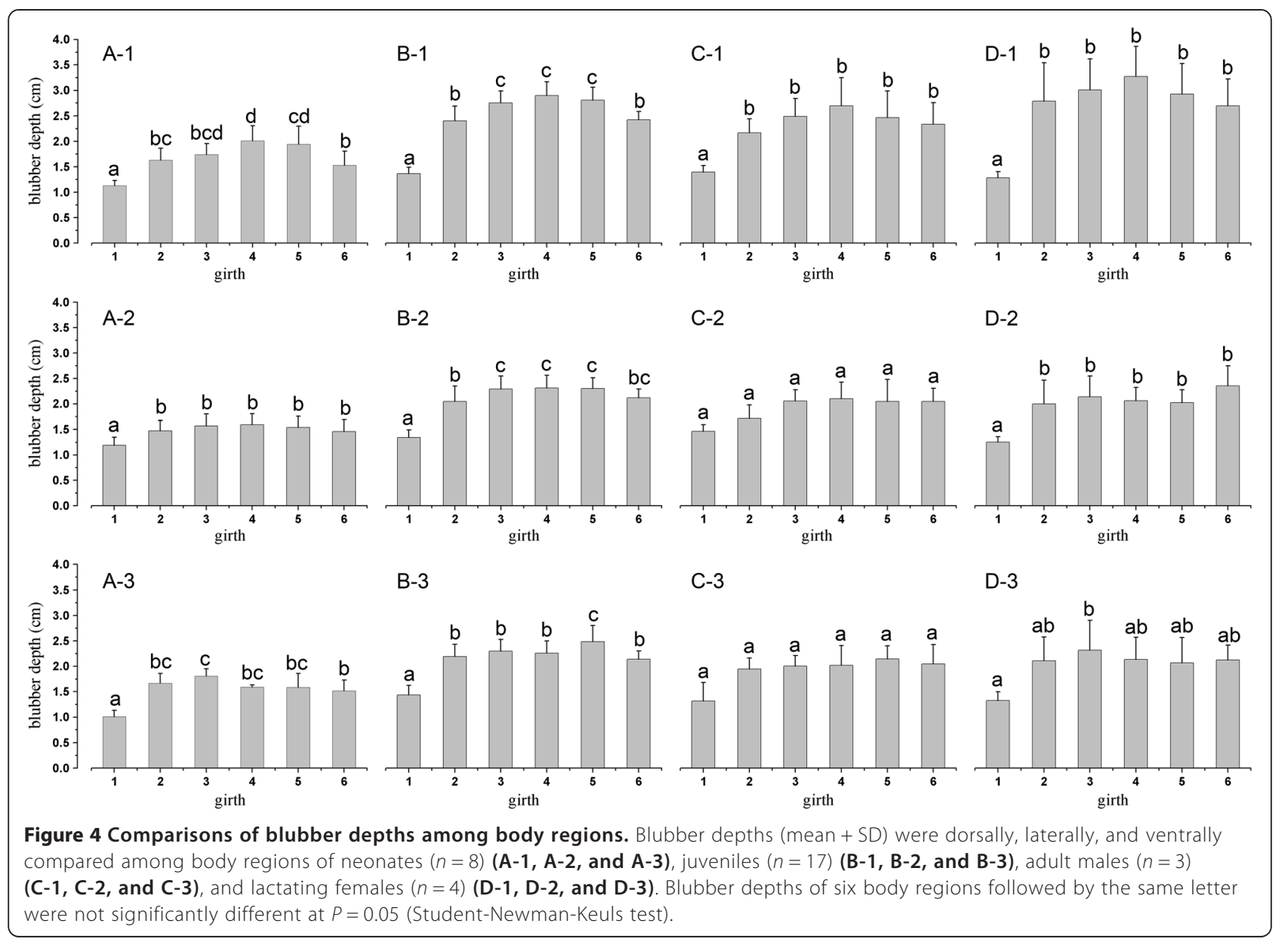

significant difference was apparent only in the umbilicus region. In contrast, juvenile blubber was thicker at lateral and ventral abdominal sites than that of the lactating females, though a significant difference was apparent only in the genital slit region.

\section{The inner blubber layer}

Posterior to the head, across life history categories, the pattern in distribution of the inner blubber layer was topographically consistent with that of full-depth blubber (Figures 3 and 5). Thickness of the inner layer in the dorsal region gradually increased from the axillary, peaked in the umbilical, and declined to the anal region (Figure 6). However, thickness of the inner layer in the thoracicabdominal region was uniform both laterally and ventrally. Posterior to the head, mean inner blubber thicknesses of the dorsal, lateral, and ventral regions differed significantly across life history groups (neonates: $F_{2,96}=14.618, P<$ 0.01 ; juvenile: $F_{2,227}=97.113, P<0.01$; adult males: $F_{2,38}=$ 43.562, $P<0.01$; lactating females: $F_{2,53}=38.010, P<0.01$ ). Additionally, mean inner blubber thickness was significantly thicker in the dorsal region (neonates: $0.39 \mathrm{~cm}$, juveniles: $0.70 \mathrm{~cm}$, adult males: $0.54 \mathrm{~cm}$ and lactating females: $0.81 \mathrm{~cm}$ ) than that in the lateral (neonates: $0.32 \mathrm{~cm}$, juveniles: $0.44 \mathrm{~cm}$, adult males: $0.35 \mathrm{~cm}$ and lactating females: $0.44 \mathrm{~cm}$ ) and ventral regions (neonates: $0.32 \mathrm{~cm}$, juveniles: $0.43 \mathrm{~cm}$, adult males: $0.37 \mathrm{~cm}$, and lactating females: $0.43 \mathrm{~cm}$ ) (Student-Newman-Keuls test, $P<0.05$ ), but no significant difference was apparent between the lateral and ventral regions. The dorsal inner layer was thicker around the girth than that at the corresponding lateral and ventral sites in the thoracic-abdominal region (Figure 5). In addition, significant differences were found in most girths posterior to the head of juveniles, adult males, and lactating females, but only in the umbilical region of neonates. Among life history categories, the inner layer of neonates was significantly thinner at dorsal sites than that it was for lactating females and juveniles, but the inner blubber layer in juveniles was thinner at the dorsal sites posterior to the head than that in lactating females, though the significance in difference was not found (Table 4). No significant differences in the inner blubber thickness were found at the lateral and ventral sites among life history groups. 
Table 3 Comparisons of blubber depths among life history categories

\begin{tabular}{|c|c|c|c|}
\hline Body region and aspect & Neonates $(n=8)$ & Juveniles $(n=17)$ & Lactating females $(n=4)$ \\
\hline \multicolumn{4}{|l|}{ Head } \\
\hline Dorsal & $1.13 \pm 0.10 \mathrm{~A}$ & $1.37 \pm 0.12 \mathrm{~B}$ & $1.29 \pm 0.12 B$ \\
\hline Lateral & $1.19 \pm 0.16$ & $1.34 \pm 0.15$ & $1.25 \pm 0.11$ \\
\hline Ventral & $1.01 \pm 0.13 \mathrm{~A}$ & $1.43 \pm 0.19 B$ & $1.33 \pm 0.17 \mathrm{~B}$ \\
\hline \multicolumn{4}{|l|}{ Axillary } \\
\hline Dorsal & $1.63 \pm 0.24 \mathrm{~A}$ & $2.40 \pm 0.29 B$ & $2.79 \pm 0.75 B$ \\
\hline Lateral & $1.47 \pm 0.20 \mathrm{~A}$ & $2.04 \pm 0.31 B$ & $2.00 \pm 0.47 \mathrm{~B}$ \\
\hline Ventral & $1.67 \pm 0.19 \mathrm{~A}$ & $2.19 \pm 0.24 B$ & $2.11 \pm 0.47 \mathrm{~B}$ \\
\hline \multicolumn{4}{|l|}{ Mid-thorax } \\
\hline Dorsal & $1.74 \pm 0.22 \mathrm{~A}$ & $2.75 \pm 0.24 \mathrm{~B}$ & $3.01 \pm 0.61 \mathrm{~B}$ \\
\hline Lateral & $1.57 \pm 0.23 \mathrm{~A}$ & $2.29 \pm 0.25 B$ & $2.14 \pm 0.41 B$ \\
\hline Ventral & $1.80 \pm 0.15 \mathrm{~A}$ & $2.30 \pm 0.23 B$ & $2.32 \pm 0.59 \mathrm{~B}$ \\
\hline \multicolumn{4}{|l|}{ Umbilicus } \\
\hline Dorsal & $2.01 \pm 0.30 \mathrm{~A}$ & $2.90 \pm 0.27 \mathrm{~B}$ & $3.28 \pm 0.59 C$ \\
\hline Lateral & $1.59 \pm 0.22 \mathrm{~A}$ & $2.31 \pm 0.25 B$ & $2.06 \pm 0.26 \mathrm{~B}$ \\
\hline Ventral & $1.59 \pm 0.05 \mathrm{~A}$ & $2.26 \pm 0.24 \mathrm{~B}$ & $2.13 \pm 0.44 \mathrm{~B}$ \\
\hline \multicolumn{4}{|l|}{ Genital slit } \\
\hline Dorsal & $1.94 \pm 0.36 \mathrm{~A}$ & $2.80 \pm 0.26 \mathrm{~B}$ & $2.93 \pm 0.60 \mathrm{~B}$ \\
\hline Lateral & $1.54 \pm 0.22 \mathrm{~A}$ & $2.30 \pm 0.21 \mathrm{C}$ & $2.02 \pm 0.25 B$ \\
\hline Ventral & $1.59 \pm 0.27 \mathrm{~A}$ & $2.48 \pm 0.32 C$ & $2.07 \pm 0.50 \mathrm{~B}$ \\
\hline \multicolumn{4}{|l|}{ Anus } \\
\hline Dorsal & $1.53 \pm 0.28 \mathrm{~A}$ & $2.42 \pm 0.17 \mathrm{~B}$ & $2.70 \pm 0.53 \mathrm{~B}$ \\
\hline Lateral & $1.46 \pm 0.23 \mathrm{~A}$ & $2.12 \pm 0.17 \mathrm{~B}$ & $2.35 \pm 0.39 B$ \\
\hline Ventral & $1.52 \pm 0.21 \mathrm{~A}$ & $2.14 \pm 0.16 \mathrm{~B}$ & $2.12 \pm 0.30 \mathrm{~B}$ \\
\hline
\end{tabular}

At each site, blubber depths (mean $\pm \mathrm{SD}$ ) (cm) of life history groups followed by the same letter were not significantly different at $P=0.05$ (StudentNewman-Keuls test). There were no significant differences among life history categories at sites without letters.

\section{Discussion}

\section{Blubber structure on ultrasound images}

When surgically incised (by scalpel), two layers of blubber were visually apparent in the dorsal region of finless porpoises, but up to three layers were apparent in this same region using ultrasound. Blubber of both harbor porpoises and bottlenose dolphins has been similarly described with two visually discernable layers, which have subsequently proven to comprise three layers by combination of histological and biochemical techniques (Koopman et al. 2002; Samuel and Worthy 2004). In bottlenose dolphins, the lipid content was significantly greater and adipocytes were enlarged in the middle blubber layer, compared to that in the outer layer (McClelland et al. 2012; Struntz et al. 2004). Accordingly, greater lipid reserves in the finless porpoise middle blubber layer likely caused the distinction between it and the outer layer in echo density of ultrasound images. The hyper-echo intensity of inner layer resulted from its heterogeneous structure, which was similar to the report in fin whales (Balaenoptera physalus), wherein the inner layer is structurally complex and consists of large, loose fiber knots, and bundles (Lockyer et al. 1984).

Topographic distribution of full-depth and inner blubber Across life history groups, finless porpoise full-depth blubber was distributed in a similar manner to that of the inner blubber layer, and full-depth blubber was significantly thicker in the dorsal region than that in the lateral and ventral regions where an obvious middle layer was absent. In bottlenose dolphins, blubber depth correlated positively with lipid content and adipocyte cell size within inner and middle layers across life history stages (Struntz et al. 2004). It is also likely that lipid in finless porpoises is stored primarily in the middle and inner layers, the combined thickness of which determines blubber depth. Finless porpoise head region blubber depth was also significantly thinner than it was in the thoracic-abdominal region, similar to accounts in harbor porpoises (Koopman 1998) and belugas (Delphinapterus leucas) (Doidge 1990). Such distribution might indicate 


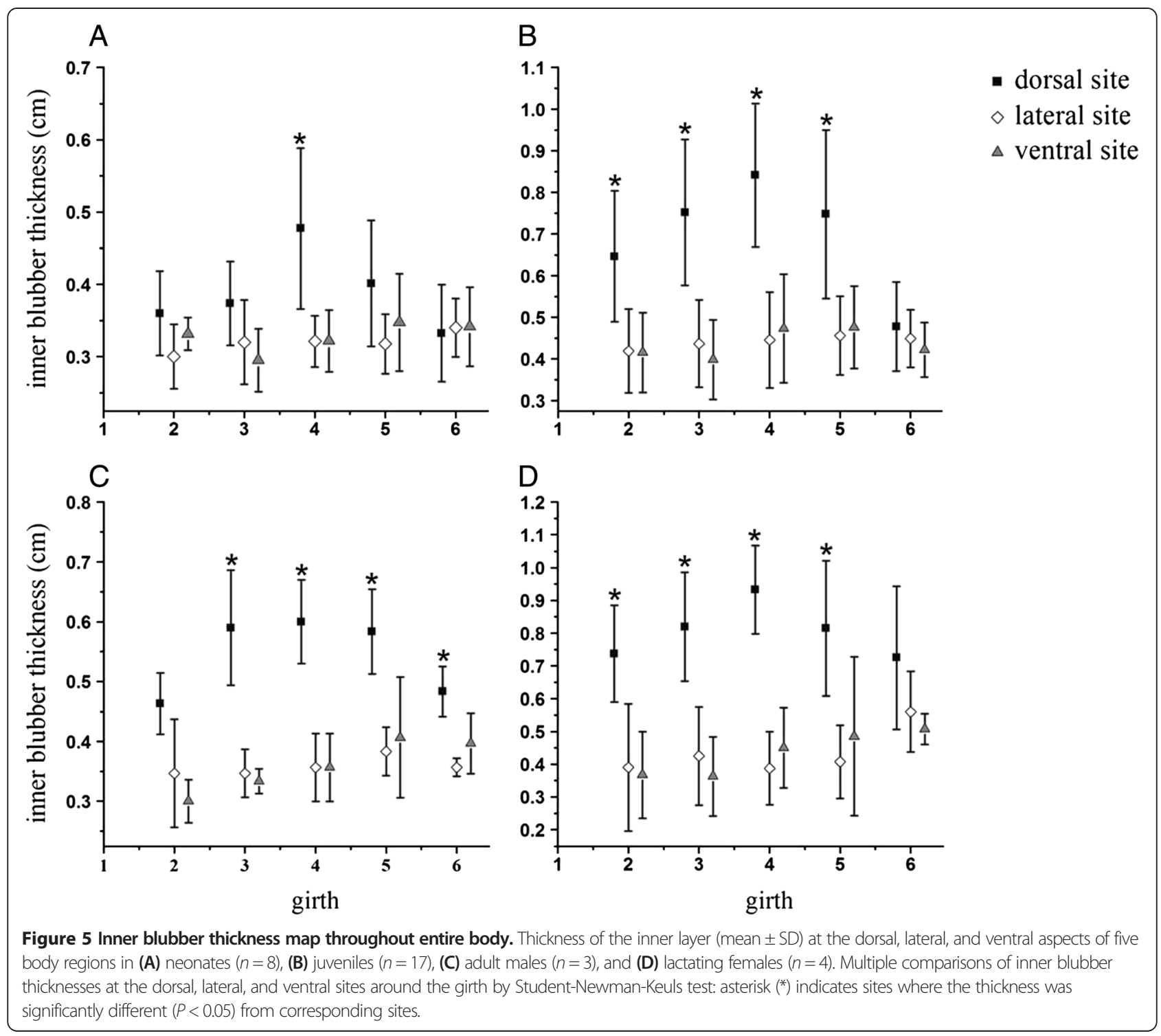

blubber in the dorsal region of the thorax, and abdomen serves as an energy reserve in finless porpoises. Furthermore, measurements of blubber depth taken from the dorsal thoracic-abdominal regions are potential indicators to appraise an individual's nutritional state.

Given their extended genital openings, and the initiation of breeding in May (Lee et al. 2013), it is possible that all lactating females in this present study had given birth within a few days of capture. Accordingly, in terms of their body condition, these females could also be regarded as later-stage pregnant individuals. Blubber of lactating females was thicker in the dorsal regions of the thorax and abdomen than it was in juveniles and neonates, which is consistent with previous findings that pregnant females possess the greatest energy reserves among life history groups (GomezCampos et al. 2011; Miller et al. 2011). In contrast, blubber of lactating females was thinner in the lateral and ventral regions of the abdomen than it was in juveniles - an observation similar to that reported for harbor seals (Phoca vitulina), in which pregnant females had significantly thinner blubber in the ventral abdominal region than non-pregnant individuals, possibly to reduce resistance for swimming (Beck and Smith 1995). However, it is also possible that the situation is comparable to that described for rabbits and sheep, wherein the maternal abdominal wall consists of thin muscles and skin layer, which acts as a thermal window (Gilbert and Power 1986; Hart and Faber 1965), and that during finless porpoise gestation, the relatively thin blubber in the lateral-ventral region of the abdomen might facilitate dissipation of heat produced from fetal metabolism, thus maintaining a more stable and suitable temperature for fetal development. Amongst all finless porpoise life history categories, blubber of neonates was consistently the thinnest. Similarly, neonatal bottlenose dolphins possess the 


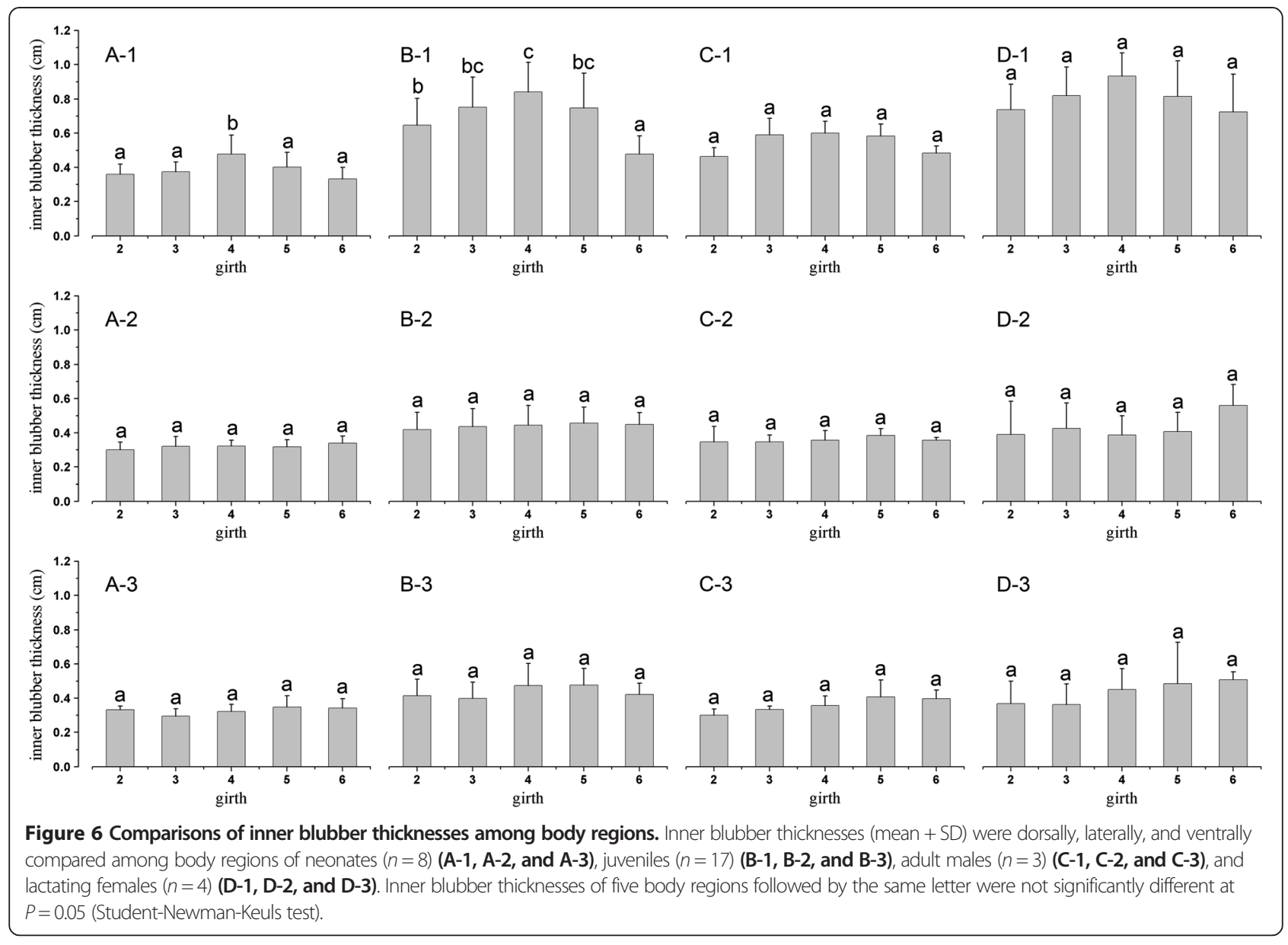

least lipid content, smallest adipocyte size, and thinnest blubber depth across ontogeny except fetuses (Struntz et al. 2004). The thin blubber in neonates may facilitate successful parturition.

\section{Adaptive significance of specific blubber distribution in finless porpoises}

During early stages of food deprivation in harbor porpoises and other toothed whales, blubber in the 'neck' region, and area lateral to the dorsal fin, is the first to be metabolized, whereas that blubber in the thoracicabdominal region tends to be more stable (Kastelein and Battum 1990). This may indicate that blubber in the thoracic-abdominal region has other important, less metabolic functions. It is well established that the dorsal fin in cetaceans vertically stabilizes the body position to prevent sideslip (Fish 2002). This also, however, limits turning performance at small radii. For instance, although various cetaceans can bank towards the inside of a turn at small degrees, only finless porpoises and belugas that lack the dorsal fin are capable of banks forming a $90^{\circ}$ angle (Fish 2002; Xiao and Wang 2005). Such ability might be advantageous in complex environments, such as the shallow, coastal, and estuarine waters inhabited by these species (Laidre et al. 2008; Jefferson and Wang 2011). In the absence of a dorsal fin, any loss in vertical stability might be compensated for by unique patterns of distribution of blubber throughout the animal. We report the dorsal blubber around the girth to be thicker than at the corresponding lateral and ventral sites in the thoracicabdominal region - a pattern of distribution inconsistent with that reported for harbor porpoises, which are otherwise similar in body size but possess a dorsal fin, in which blubber depth varies little around the girth (Koopman 1998). This pattern in blubber distribution is, however, consistent with those reported for belugas and seals (Doidge 1990; Ryg et al. 1988). Given lipids are less dense than water (Kipps et al. 2002), additional lipids stored in the dorsal region could render an animal's center of gravity deeper in the body than otherwise might be the case. This in turn might facilitate normal swimming stabilization and even rapid and agile maneuvering at small radii. Therefore, it is possible that the unusual distribution of blubber we describe for finless porpoises might compensate for the loss of the dorsal fin and be an adaptation for nimble swimming in coastal and estuarine waters. 
Table 4 Comparisons of inner blubber thicknesses among life history categories

\begin{tabular}{|c|c|c|c|}
\hline $\begin{array}{l}\text { Body region } \\
\text { and aspect }\end{array}$ & $\begin{array}{l}\text { Neonates } \\
(n=8)\end{array}$ & $\begin{array}{l}\text { Juveniles } \\
(n=17)\end{array}$ & $\begin{array}{l}\text { Lactating females } \\
(n=4)\end{array}$ \\
\hline \multicolumn{4}{|l|}{ Axillary } \\
\hline Dorsal & $0.36 \pm 0.06 \mathrm{~A}$ & $0.65 \pm 0.16 \mathrm{~B}$ & $0.74 \pm 0.15 B$ \\
\hline Lateral & $0.30 \pm 0.04$ & $0.42 \pm 0.10$ & $0.30 \pm 0.04$ \\
\hline Ventral & $0.33 \pm 0.02$ & $0.42 \pm 0.10$ & $0.37 \pm 0.13$ \\
\hline \multicolumn{4}{|l|}{ Mid-thorax } \\
\hline Dorsal & $0.37 \pm 0.06 \mathrm{~A}$ & $0.75 \pm 0.18 \mathrm{~B}$ & $0.82 \pm 0.17 \mathrm{~B}$ \\
\hline Lateral & $0.32 \pm 0.06$ & $0.44 \pm 0.11$ & $0.43 \pm 0.15$ \\
\hline Ventral & $0.30 \pm 0.04$ & $0.40 \pm 0.10$ & $0.36 \pm 0.12$ \\
\hline \multicolumn{4}{|l|}{ Umbilicus } \\
\hline Dorsal & $0.48 \pm 0.11 \mathrm{~A}$ & $0.84 \pm 0.17 \mathrm{~B}$ & $0.93 \pm 0.14 \mathrm{~B}$ \\
\hline Lateral & $0.32 \pm 0.04$ & $0.45 \pm 0.12$ & $0.39 \pm 0.11$ \\
\hline Ventral & $0.32 \pm 0.04$ & $0.47 \pm 0.13$ & $0.45 \pm 0.12$ \\
\hline \multicolumn{4}{|l|}{ Genital slit } \\
\hline Dorsal & $0.37 \pm 0.04 \mathrm{~A}$ & $0.75 \pm 0.20 \mathrm{~B}$ & $0.82 \pm 0.21 \mathrm{~B}$ \\
\hline Lateral & $0.32 \pm 0.04 \mathrm{~A}$ & $0.46 \pm 0.09 B C$ & $0.41 \pm 0.11 \mathrm{AB}$ \\
\hline Ventral & $0.35 \pm 0.07$ & $0.48 \pm 0.10$ & $0.49 \pm 0.24$ \\
\hline \multicolumn{4}{|l|}{ Anus } \\
\hline Dorsal & $0.33 \pm 0.07 \mathrm{~A}$ & $0.48 \pm 0.11 \mathrm{~A}$ & $0.73 \pm 0.22 \mathrm{~B}$ \\
\hline Lateral & $0.34 \pm 0.04 \mathrm{~A}$ & $0.45 \pm 0.07 \mathrm{~B}$ & $0.56 \pm 0.12 \mathrm{C}$ \\
\hline Ventral & $0.34 \pm 0.05 \mathrm{~A}$ & $0.42 \pm 0.07 \mathrm{~B}$ & $0.51 \pm 0.05 C$ \\
\hline
\end{tabular}

At each site, inner blubber thicknesses (mean \pm SD) $(\mathrm{cm})$ of life history groups followed by the same letter were not significantly different at $P=0.05$ (Student-Newman-Keuls test). There were no significant differences among life history categories at sites without letters.

\section{Conclusions}

Ultrasonography provided rapid and valuable insights into blubber structure, measurements, and distribution that have enabled a faster and more pleasant, in addition to potentially more reliable appraisal of the condition of a cetacean than would otherwise have proven possible using conventional approaches, such as cadaver dissection and visual examination. Our findings suggest blubber in the dorsal region of the thorax and abdomen functions both as an energy reserve and for thermal insulation. Furthermore, measurements of blubber depth taken from this region likely provide an indication of body condition in this subspecies. However, further efforts are required to understand structure and functions of blubber in the 'neck' region of odontocetes, which was ignored generally in previous and present studies. Finally, the distribution of blubber with the absence of a dorsal fin in finless porpoises might facilitate stabilization and maneuvering in coastal and estuarine waters, although additional research is required to investigate this matter further.

\section{Competing interests}

The authors declare that they have no competing interests.
Authors' contributions

$\mathrm{YH}$ and DW designed and conceived the project. XZ and JJ conducted all the experimental procedures and data collection and analysis. $\mathrm{XZ}$ and $\mathrm{YH}$ wrote the paper. All authors read and approved the final manuscript.

\section{Acknowledgements}

We thank Shenglun Zhang, Mingen Yin, and other staff in the Ocean World of Penglai for the assistance in the carcass collection. We are especially grateful to Xiong Li and Jianrong Zhang for the advice on ultrasound and physiological examinations of this project. This study was financially supported by the National Natural Science Foundation of China (No. 31430080).

\section{Author details}

${ }^{1}$ Institute of Hydrobiology, Chinese Academy of Sciences, 7 South Donghu Road, Wuchang District, Wuhan 430072, China. ${ }^{2}$ University of Chinese Academy of Sciences, 19 Yuquan Road, Shijingshan District, Beijing 100049, China.

Received: 14 November 2014 Accepted: 2 February 2015

Published online: 12 February 2015

\section{References}

American Society of Mammalogists (1961) Standardized methods for measuring and recording data on the smaller cetaceans. J Mammal 42:471-6

Beck GG, Smith TG (1995) Distribution of blubber in the northwest Atlantic harp seal, Phoca groenlandica. Can J Zool 73(11):1991-8

Brook F (2001) Ultrasonographic imaging of the reproductive organs of the female bottlenose dolphin, Tursiops truncatus aduncas. Reproduction 121(3):419-28

Charlier P, Chaillot P-F, Watier L, Ménétrier M, Carlier R, Cavard S, Hervé C, de la Grandmaison GL, Huynh-Charlier I (2013) Is postmortem ultrasonography a useful tool for forensic purposes? Med Sci Law 53(4):227-34

Dearolf JL, McLellan WA, Dillaman RM, Frierson D, Pabst DA (2000) Precocial development of axial locomotor muscle in bottlenose dolphins (Tursiops truncatus). J Morphol 244(3):203-15

Doidge DW (1990) Integumentary heat loss and blubber distribution in the beluga, Delphinapterus leucas, with comparisons to the narwhal, Monodon monoceros. Can Bull Fish Aquat Sci 224:129-40

Fish FE (2002) Balancing requirements for stability and maneuverability in cetaceans. Integr Comp Biol 42(1):85-93

Gao A, Zhou K (1993) Growth and reproduction of three populations of finless porpoise, Neophocaena phocaenoides, in Chinese waters. Aquat Mamm 19(1):3-12

Gilbert RD, Power GG (1986) Fetal and uteroplacental heat production in sheep. J Appl Physiol 61(6):2018-22

Gomez-Campos E, Borrell A, Aguilar A (2011) Assessment of nutritional condition indices across reproductive states in the striped dolphin (Stenella coeruleoalba). J Exp Mar Biol Ecol 405(1):18-24

Hart FM, Faber JJ (1965) Fetal and maternal temperatures in rabbits. J Appl Physiol 20(4):737

Heng HG, Selvarajah GT, Lim HT, Ong JS, Lim J, Ooi JT (2009) Serial postmortem abdominal radiographic findings in canine cadavers. Forensic Sci Int 192(1-3):43-7

Jefferson TA, Wang JY (2011) Revision of the taxonomy of finless porpoises (genus Neophocaena): the existence of two species. J Mar Anim Ecol 4(1):3-16

Kastelein R, Van Battum R (1990) The relationship between body weight and morphological measurements in harbour porpoises (Phocoena phocoena) from the North Sea. Aquat Mamm 16:48-52

Kipps EK, McLellan WA, Rommel SA, Pabst DA (2002) Skin density and its influence on buoyancy in the manatee (Trichechus manatus latirostris), harbor porpoise (Phocoena phocoena), and bottlenose dolphin (Tursiops truncatus). Mar Mammal Sci 18(3):765-78

Koopman HN (1998) Topographical distribution of the blubber of harbor porpoises (Phocoena phocoena). J Mammal 79(1):260-70

Koopman H, Pabst D, McLellan W, Dillaman R, Read A (2002) Changes in blubber distribution and morphology associated with starvation in the harbor porpoise (Phocoena phocoena): evidence for regional differences in blubber structure and function. Physiol Biochem Zool 75(5):498-512

Laidre KL, Stirling I, Lowry LF, Wiig O, Heide-Jørgensen MP, Ferguson SH (2008) Quantifying the sensitivity of arctic marine mammals to climate-induced habitat change. Ecol Appl 18(sp2):S97-125 
Lee YR, An YR, Park KJ, Sohn H, An DH, Kim SA (2013) Age and reproduction of the finless porpoises, Neophocaena asiaeorientalis, in the Yellow Sea, Korea. Anim Cells Syst 17(5):366-73

Lockyer CH, McConnell LC, Waters TD (1984) The biochemical composition of fin whale blubber. Can J Zool 62(12):2553-62

McClelland SJ, Gay M, Pabst DA, Dillaman R, Westgate AJ, Koopman HN (2012) Microvascular patterns in the blubber of shallow and deep diving odontocetes. J Morphol 273(8):932-42

Mellish J-AE, Horning M, York AE (2007) Seasonal and spatial blubber depth changes in captive harbor seals (Phoca vitulina) and Steller's sea lions (Eumetopias jubatus). J Mammal 88(2):408-14

Miller CA, Reeb D, Best PB, Knowlton AR, Brown MW, Moore MJ (2011) Blubber thickness in right whales Eubalaena glacialis and Eubalaena australis related with reproduction, life history status and prey abundance. Mar Ecol-Prog Ser 438:267-83

Montie EW, Garvin SR, Fair PA, Bossart GD, Mitchum GB, McFee WE, Speakman T, Starczak VR, Hahn ME (2008) Blubber morphology in wild bottlenose dolphins (Tursiops truncatus) from the Southeastern United States: influence of geographic location, age class, and reproductive state. J Morphol 269(4):496-511

Read AJ (1990) Estimation of body condition in harbor porpoises, Phocoena phocoena. Can J Zool 68(9):1962-6

Ryg M, Smith TG, Øritsland NA (1988) Thermal significance of the topographical distribution of blubber in ringed seals (Phoca hispida). Can Bull Fish Aquat Sci 45(6):985-92

Ryg M, Lydersen C, Markussen NH, Smith TG, Øritsland NA (1990) Estimating the blubber content of phocid seals. Can Bull Fish Aquat Sci 47(6):1223-7

Samuel AM, Worthy GA (2004) Variability in fatty acid composition of bottlenose dolphin (Tursiops truncatus) blubber as a function of body site, season, and reproductive state. Can J Zool 82(12):1933-42

Struntz D, McLellan W, Dillaman R, Blum J, Kucklick J, Pabst D (2004) Blubber development in bottlenose dolphins (Tursiops truncatus). J Morphol 259(1):7-20

Xiao J-Q, Wang D (2005) Construction of ethogram of the captive Yangtze finless porpoise, Neophocaena phocaenoides asiaeorientalis. Acta Hydrobiol Sin 29(3):253-8 (in Chinese with an English abstract)

\section{Submit your manuscript to a SpringerOpen ${ }^{\circ}$ journal and benefit from:}

- Convenient online submission

- Rigorous peer review

- Immediate publication on acceptance

- Open access: articles freely available online

- High visibility within the field

- Retaining the copyright to your article

Submit your next manuscript at $>$ springeropen.com 